\title{
Productivity Differences and the Dynamic Effects of Labor Movements
}

\author{
Paul Klein ${ }^{a}{ }^{\text {Gustavo Ventura }}{ }^{b, *}$ \\ ${ }^{a}$ University of Western Ontario \\ ${ }^{b}$ University of Iowa
}

This version: April 7, 2007

\begin{abstract}
This paper is about the interaction between differences in TFP and barriers to labor mobility. We use a growth model with endogenous labor movements to provide a quantitative assessment of the effects on output, capital accumulation and welfare of removing barriers to labor mobility. We parameterize this model so that it is broadly consistent with evidence on historical international labor movements, and apply it to two cases: the enlargement of the European Union and the (hypothetical) creation of a common labor market in NAFTA. Our main finding is that there are large resulting gains in terms of output and welfare. In the European case, the output gains after fifty years are about 1.7-4.5\%, and in the NAFTA case they are about 1.3-3.0\%. Young individuals from "new" Europe experience a rise in welfare corresponding to an increase in consumption of 2.7$5.9 \%$, whereas young Mexicans gain about 2.0-4.3\%. The losses of young residents of rich locations are much smaller. We also find that capital accumulation strongly magnifies the output effects of labor mobility.
\end{abstract}

Keywords: TFP, Cross-country Income Differences, Labor Mobility, Capital mobility. JEL classification: O11, O40, E13.

${ }^{*}$ We thank Francesco Caselli, Jonathan Heathcote, Lutz Hendricks, Barry Ickes, Peter Klenow, Andrés Rodriguez-Clare, Richard Rogerson and seminar participants at the NBER Summer Institute (Economic Growth), the Midwest Macro Meetings, the North American Winter Meeting of the Econometric Society, SED Meetings, the Canadian Macroeconomics Study Group, the PSU-Cornell Macro Conference, the TorontoWestern Conference, ITAM, Vanderbilt, Rice, SUNY-Stony Brook and Guelph, for useful comments and suggestions. Earlier versions of this paper circulated under the title "Do Migration Restrictions Matter?". The usual disclaimer applies.

Email: paul.klein@uwo.ca and gustavo-ventura@uiowa.edu. 


\section{Introduction}

This paper is about the interaction between Total Factor Productivity (TFP) differences and barriers to labor mobility. We ask: in the presence of empirically plausible TFP differences, what are the implications for output and welfare of removing barriers to labor mobility? We address this question in the context of a two-location growth model, where heterogeneous individuals decide whether or not to move, taking into account costs of moving as well as possible skill losses associated with a change of locations. We parameterize this model to assess the consequences of the enlargement of the European Union, and a hypothetical creation of a common labor market within the North American Free Trade Area (NAFTA). Our findings indicate that there are large unrealized output and welfare gains associated with the removal of restrictions to labor movements.

There are two key reasons for thinking that these issues are of fundamental importance. Firstly, there are large differences in output per worker across countries. This fact has been extensively documented by several authors; see McGrattan and Schmitz (2000) for a survey of this evidence. For example, between OECD countries and non-OECD countries, the output-per-worker gap is in excess of a factor 4. As we calculate later in the paper, the difference between members of NAFTA amounts to a factor of 2.6 (Canada and U.S. vs Mexico). Recent work has concluded that large TFP differences are what accounts for the bulk of these differences in output per worker. Put differently, differences in inputs are not nearly enough to account for the observed disparities. This has been thoroughly documented by Caselli (2004), Hall and Jones (1999), Hendricks (2002), Klenow and Rodriguez-Clare (1997), Parente and Prescott (2000) and Prescott (1998), among others.

Secondly, these output and productivity differences coexist with widespread and severe barriers to labor movements that restrict labor flows from poor (relatively unproductive) locations to rich (relatively productive) ones. These barriers have been in place for a long time; in the case of the United States, since the 1920's. By contrast, in the nineteenth and early twentieth century, immigration into the U.S. and many other countries was largely unregulated. ${ }^{1}$ In a nutshell, the problem with barriers to labor movements in the presence of productivity differences, other things being equal, is that they lead to differences in the marginal product

${ }^{1}$ O'Rourke and Williamson (1999) and Hatton and Williamson (1998), among others, document the large movements of individuals in the nineteenth and early twentieth century. Prior to the enactment of restrictions, migration flows were much larger than today, even though economic incentives to move (i.e. output per worker differences) were arguably smaller, and transportation costs were larger. 
of labor. This naturally creates an efficiency reason for workers to move from low to high productivity locations. However, the barriers prevent this from happening to a significant extent. This simple reasoning strongly suggests that labor is misallocated across locations. Capital accumulation does not mitigate this problem. Indeed, it magnifies it; as we argue below, output gains for the aggregate (world) economy from labor mobility are much larger when capital can be accumulated.

We study an economy comprised of two locations (regions). Individuals have finite lives and are heterogeneous in terms of their age, skills, and how costly it is for each of them to change locations. There is a single dated good, which is produced using three factors under constant returns to scale: capital, labor and land. Capital moves at no cost across locations, equating rates of return. Land is fixed in every location and constitutes an essential factor of production. Labor is imperfectly mobile since individuals face migration costs. Moving from one location to the other entails a resource cost that individuals cannot borrow against future income to pay. In addition, moving involves a proportional loss of skills (skills are only imperfectly portable) and individuals face a psychic cost associated with residing in a location different from their birthplace. In this environment, individuals decide how much to consume and save in the form of capital and land, as well as whether and when to move.

Our model economy has a number of features that make it an appropriate vehicle for the study of labor mobility. First, the presence of land as a fixed factor avoids a degenerate distribution of population across locations when moving costs are zero. By contrast, if returns to capital and labor jointly are constant, and TFP differs across countries, then mobility of capital and labor implies that the low-productivity economy vanishes. Diminishing returns to capital and labor jointly implies that the low-TFP economy survives. However, as we demonstrate later on, with a realistic (small) land share, some rather striking arithmetic kicks in: even small productivity differences imply large movements of labor in the long run if wages are to be nearly equal.

Second, our environment allows us to explore the consequences of labor mobility when capital is mobile and can be accumulated. Notice that in a static environment, where returns to capital and labor jointly are constant and TFP is common to both countries, mobility of capital or labor is sufficient to equalize wages and returns on capital; in contrast, when there is a third factor in fixed supply and/or productivity differences, capital and labor would have to move to equate wages, returns to capital and land rents. In a dynamic environment, we show that the output consequences of labor movements are magnified by the accumulation of 
capital. This happens because under productivity differences, a reallocation of labor (from the low to the high productivity location) leads to an increase in the rate of return to capital in the short run. This in turn fosters capital accumulation and, as a result, the world's capital stock is larger in the long run.

Finally, the model can potentially generate protracted patterns of labor movements due to the model features mentioned above. We exploit this model property to impose discipline on our choice of parameter values. Specifically, we conduct exercises in a model parameterized to be broadly consistent with historical evidence on migration phenomena. As individuals gradually move, capital follows, both instantaneously and over time. Instantaneously, capital "chases" labor, since an increase in labor in a location increases the marginal product of capital there. Over time, an increase in the (common) world rate of return on capital encourages the accumulation of a larger world capital stock.

To sum up, the model we study allows us to examine, quantitatively, the consequences of barriers to labor mobility on output and capital accumulation over time. In welfare terms, we determine who gains, who loses and how much. This latter point is of fundamental importance for an assessment of reforms to current policies, as well as to shed light on what is needed to make these potential reforms implementable.

When we explore implications of the framework under calibrated parameter values, we find that lifting barriers to labor movements leads to sizeable long-run movements of labor in conjunction with large increases in total output and capital. This holds true even for TFP differences of a moderate size. Our results also show that abstracting from capital accumulation and the reallocation of the capital stock across locations can result in a misleading picture of the consequences of barriers to labor mobility. For instance, when the output-perworker ratio between locations is 2 in the absence of labor movements, at most about $53 \%$ of the total change in world output across steady states is due to labor movements alone; the remainder is due to capital accumulation and changes in the allocation of the capital stock across locations.

We subsequently apply the model to assess the consequences of the the enlargement of the European Union and to the hypothetical creation of a common labor market within NAFTA. These cases share very similar initial fractions of the labor force in the rich (poor) location, but differ as natives of the poor location in North America (Mexico) are relatively less educated than "new" Europeans. As a result, the importance of productivity differences in 
accounting for observed disparities between locations is greater in Europe than in NAFTA. We find that a removal of labor mobility restrictions would raise aggregate output by about $8 \%$ in the long run in the case of Europe, and about 10.5\% in the North American case. These output gains are similar to those associated with eliminating a worldwide capital income tax between 40 and 45 percent. After 50 years, the output effects range from $1.7-4.5 \%$ in the case of Europe and from 1.3-3.0\% in the NAFTA case. Regarding welfare, gains are distributed unequally among those alive at the time of elimination of restrictions. Rich region young natives mostly lose, and rich location old natives and poor location natives mostly gain from the removal of barriers. Young natives of the rich location lose about $0.2-0.6 \%$ in the case of Europe and about 0.1-0.3\% in the case of NAFTA. But those who gain, gain substantially more. Young natives in the poor location gain between 2.7-5.9\% in the European case, and $2.0-4.3 \%$ in the NAFTA case.

Overall, these findings suggest that there are unrealized welfare and output gains, that are large by the standards of the macroeconomic and applied general equilibrium literature. They also strongly motivate the further study of specific policies aimed at capturing these gains, or at least a part of them.

Related Literature Given its emphasis on the effects of labor mobility, this paper is related to a number of papers which quantify the effects of migration policy. Examples include Borjas (1995) and Hamilton and Whalley (1984), and more recently Moses and Letnes (2004) and Walmsley and Winters (2003), who provide quantitative estimates of the effects of immigration and labor mobility in static frameworks. While Borjas (1995) studied the benefits for the United States of increasing the number of immigrants in the labor force, the others investigated the consequences for the world of a more efficient allocation of the labor force across countries. The present paper differs from the above in situating the analysis of labor mobility in a dynamic environment, where individuals make savings and moving decisions. This allows us, among other things, to understand the welfare consequences of removing these barriers: who gains, who loses and how much.

The present paper is also related to recent papers that examined mobility of factors in dynamic environments. Examples include Ben-Gad (2004), Burstein and Monge (2005), Caselli and Feyrer (2005), Gourinchas and Jeanne (2006), Urrutia (1998) and Vandenbroucke (2007). Among the aforementioned papers, Gourinchas and Jeanne (2006) consider the impact of an efficient reallocation of capital, and find that welfare gains associated with 
unrestricted capital mobility are quantitatively small. In a dynamic framework, under TFP differences and immobile labor, capital accumulation dictates that the rate of return to capital is equalized across countries in the long run even in the absence of capital mobility. Thus, further liberalization of capital movements only accelerates the transition to the steady state. Our findings should be viewed as complimentary to the findings of these authors. Our results show that under productivity differences, the allocation of capital across countries is linked to the allocation of labor. In turn, the reallocation of factors following the removal of barriers to labor mobility has quantitatively substantial consequences for the long-run size of the capital stock. Thus, there are large gains associated with the accumulation of capital and a change in its division across locations, but these gains can only be realized in the presence of labor mobility.

In a paper more closely related to ours, Urrutia (1998) studied who migrates and the implications of migration policy on welfare in a two-country world populated by dynastic households where wage differences in the long run are due exclusively to TFP differences. ${ }^{2}$ A critical feature of that paper is the assumption of costless capital mobility under constant returns to capital and labor jointly. In these circumstances, labor movements cannot reduce or eliminate differences in the marginal product of labor across countries. What labor movements can do is to reduce the relative size of the low TFP country. Unlike our model, Urrutia's model has the implication that all migration following the lifting of restrictions takes place within a very short period of time. This result is due to the dynastic structure of the model: if it is not worthwhile for a dynasty to move in an initial period, then it is typically never worthwhile.

The paper is organized as follows. In Section 2, we lay out the model environment. In Section 3, we describe our model in more detail and assign values to those parameters that will remain constant throughout our computational experiments. In Section 4, we explore the quantitative properties of our framework by discussing the results for a number of hypothetical cases. In Section 5 we study in detail the cases of the enlargement of the European Union and the creation of a common labor market within NAFTA. Section 6 concludes.

\footnotetext{
${ }^{2}$ Another paper featuring endogenous migration decisions is Simpson (2000), who studies the interaction between the skill acquisition choice and the migration choice in a two-period overlapping generations model.
} 


\section{A Growth Model with Labor Movements}

We describe below the economic environment we use to assess the dynamic effects of labor mobility. We present first a basic description of the environment and notation. We subsequently define the decision problem of individuals recursively, and elaborate on equilibrium conditions. We close the section with comments on the implications of the model.

Locations There are two locations where individuals can work and live, $x=\mathcal{R}$ and $x=\mathcal{P}$. These locations potentially differ in terms of Total Factor Productivity (TFP) and the quantities of land available. Location $\mathcal{R}$ has $F_{\mathcal{R}}$ units of land, and location $\mathcal{P}$ has $F_{\mathcal{P}}$ units of land. These units of land are by assumption fixed and immobile.

Technology A single good is produced in each location, using a CRS production function that uses capital $(K)$, labor $(L)$ and land given by

$$
Y_{x}(t)=G\left(K_{x}(t), L_{x}(t), F_{x} ; A_{x}\right)=A_{x} K_{x}^{\lambda}(t) L_{x}(t)^{\eta} F_{x}^{1-\lambda-\eta}
$$

for $x \in\{\mathcal{R}, \mathcal{P}\}$, where $A_{x}$ stands for TFP in location $x$. Capital depreciates at the rate $\delta \in[0,1]$.

Preferences, Endowments and Heterogeneity Time is discrete. The economy is populated by a continuum of individuals of total measure one. We denote the populations of the respective locations at $t$ by $N_{\mathcal{R}}(t)$ and $N_{\mathcal{P}}(t)$, which satisfy $N_{\mathcal{R}}(t)+N_{\mathcal{P}}(t)=1$. Individuals are born at the beginning of each period $t$ in each location, in proportion to the prior population of this location. A person's age $j$ belongs to the set $\mathcal{J}=\{1,2, \ldots, J\}$, where $J$ denotes the maximum age.

Individuals born in a given location differ with respect to their psychic cost of living away from home, $\gamma(i)$. Their type, $i$, is realized at birth and does not change as the person gets older. The distribution of types is described by a density $\alpha(i)$. Being of type $i$ implies a utility cost $\gamma(i)$ per period after having moved to a new location.

Let $c(j)$ denote individual consumption at age $j$. The objective of a person of type $i$ born 
in $t$ in location $y$ is to maximize

$$
\sum_{j=1}^{J} \beta^{j-1}\left[u(c(j))-\gamma(i) \cdot \chi_{\{x(j) \neq y\}}(j)\right]
$$

where $x(j)$ is the location at age $j \in \mathcal{J}, y \in\{\mathcal{R}, \mathcal{P}\}$ is the birthplace and $\chi$ is the indicator function. The function $u(\cdot)$ is continuous, strictly increasing and strictly concave. Individuals are born with no assets and are endowed with birthplace-dependent efficiency units of labor $e(j, y)$. Beyond the standard dependence on age, the dependence of the function $e$ on individuals' birthplace allows for differences in the quality of labor across regions.

Migration If a person moves, her effective endowment is $e(j, y)(1-\theta)$ for all $j \geq j_{0}$, where $j_{0}$ is the age of arrival to the new location. Otherwise, it equals $e(j, y)$. We note that this assumption implies that the the loss of efficiency units associated with migration for an individual is permanent. Individuals can move from one location to another by paying a fixed resource cost $m$. Paying $m$ in period $t$ entitles the individual to start period $t+1$ in the other location. Individuals are allowed to change locations (move) only once in their lives (i.e. "return" migration is not allowed). ${ }^{3}$

Individuals are unrestricted in their choice of asset position except when they are about to die or have decided to move, in which case their asset choice must be non-negative. Thus, in the latter case, the fixed cost $m$ cannot exceed individual's labor income plus the gross return on their asset holdings.

Markets Individuals supply labor services in competitive markets. As above, denote current location by $x \in\{\mathcal{R}, \mathcal{P}\}$ and birthplace by $y \in\{\mathcal{R}, \mathcal{P}\}$. Then if $x=y$, i.e. the individual has not moved, labor income equals $w_{x}(t) e(j, x)$, and if $y \neq x$, it equals $w_{x}(t) e(j, y)(1-\theta)$, where $w_{x}(t)$ stands for the wage rate at time $t$ in location $x$.

Individuals can accumulate two risk-free assets, capital $(k)$ and land $(f)$, which pay competitive rates of return. Both capital and land are perfectly divisible. Purchasing land in period $t$ entitles the buyer to the proceeds from renting it out in periods $t+1, t+2, t+3$, and so on. Individuals are allowed to buy and sell land from both locations.

\footnotetext{
${ }^{3}$ We make this assumption since it greatly simplifies the computation of decision rules and equilibria. Our assumption is largely innocuous. Although the psychic cost might dictate return migration choices of retirees, it is unlikely to have much of an impact on labor movements.
} 
Capital moves costessly across locations. Thus, $r^{k}(t)$ is the common "world" rate of return on capital. In equilibrium, since capital and land are identical assets from the perspective of an individual, the two types of land also have this rate of return in the following sense. Let $p_{x}(t)$ be the price of land in region $x$ in period $t$. Let $R_{x}(t)$ be the rental rate on (equal to the marginal product of) land in region $x$ in period $t$. Then

$$
\frac{p_{x}(t)+R_{x}(t)}{p_{x}(t-1)} \equiv 1+r_{x}^{f}(t)=1+r^{k}(t)=1+r(t)
$$

for all $x \in\{\mathcal{R}, \mathcal{P}\}$ and all $t$. Thus, the previous no-arbitrage relationship implies that, in the absence of any speculative bubble, the current prices of land will equal the present discounted value of land rental rates, accruing from tomorrow on. That is, for all $x \in\{\mathcal{R}, \mathcal{P}\}$,

$$
p_{x}(t)=\sum_{s=1}^{\infty} Q_{t, s} R_{x}(t+s)
$$

where $Q_{t, s}=\prod_{i=1}^{s}(1+r(t+i))^{-1}$.

Decision problem We now describe an individual's decision problem recursively. Relevant for this decision will be wages in the two locations as well as world interest rates. The time-dependence of these objects will translate into the time-dependence of decision rules and value functions.

We note first that given common rates of return on land and capital, the asset position of an individual is summarized by a single state variable (i.e. there is no portfolio composition problem and thus all that matters is the total value of assets, properly defined). Consider the budget constraint of an individual of type $i$ at age $j$ and time $t$ in location $x$, who has not moved in the past. He enters the period with capital and land holdings $k_{j}$ and $f_{x, j}$ respectively. He faces a rate of return on capital holdings $r(t)$ and a land rental rate $R_{x}^{f}(t)$. He can buy and sell land at the end of the period at the price $p_{x}(t)$ as well as accumulate capital for the next period. Hence, his budget constraint reads

$$
\begin{gathered}
c_{j}+k_{j+1}+\sum_{x \in\{\mathcal{R}, \mathcal{P}\}} p_{x}(t) f_{x, j+1}+\varphi_{j} m= \\
(1+r(t)) k_{j}+\sum_{x \in\{\mathcal{R}, \mathcal{P}\}}\left(R_{x}(t)+p_{x}(t)\right) f_{x, j}+w_{x}(t) e(j, x)
\end{gathered}
$$

where $\varphi_{j}$ takes the value of 1 if he chooses to start next period in the other location, and 0 otherwise. Since, for $x \in\{\mathcal{R}, \mathcal{P}\}, R_{x}(t)+p_{x}(t)=(1+r(t)) p_{x}(t-1)$ by no arbitrage, we can 
write the budget constraint as

$$
c_{j}+k_{j+1}+\sum_{x \in\{\mathcal{R}, \mathcal{P}\}} p_{x}(t) f_{x, j+1}+\varphi_{j} m=(1+r(t))\left[k_{j}+\sum_{x \in\{\mathcal{R}, \mathcal{P}\}} p_{x}(t-1) f_{x, j}\right]+w_{x}(t) e(j, x)
$$

Therefore, defining current assets as $a_{j} \equiv k_{j}+\sum_{x \in\{\mathcal{R}, \mathcal{P}\}} p_{x}(t-1) f_{x, j}$ and desired assets for the next period as $a_{j+1} \equiv k_{j+1}+\sum_{x \in\{\mathcal{R}, \mathcal{P}\}} p_{x}(t) f_{x, j+1}$, the budget constraint becomes

$$
c_{j}+a_{j+1}+\varphi_{j} m=(1+r(t)) a_{j}+w_{x}(t) e(j, x)
$$

The above arguments determine that the state of an individual is summarized by the vector $z=(a, i, j, x, y)$, where $x$, as before, denotes the location where he is currently living and $y$ denotes the location where the individual was born. Let $-x$ denote the "other" location so that $-\mathcal{R}=\mathcal{P}$ and vice versa.

The value function $v_{t}(z)$ obeys the following recursions. If $x \neq y$ (i.e. the individual has migrated in the past and migration is not feasible)

$$
v_{t}(a, i, j, x,-x)=\max _{\left(a^{\prime}, c\right)}\left\{u(c)-\gamma(i)+\beta v_{t+1}\left(a^{\prime}, i, j+1, x,-x\right)\right\}
$$

subject to

$$
\begin{gathered}
c+a^{\prime} \leq a(1+r(t))+(1-\theta) w_{x}(t) e(j,-x), \\
a^{\prime} \geq 0, \text { for } j=J \\
v_{t}(a, i, J+1, x,-x) \equiv 0 .
\end{gathered}
$$

If $x=y$ (i.e. migration is feasible)

$$
v_{t}(a, i, j, x, x)=\max _{\left(a^{\prime}, c, \varphi\right)}\left\{u(c)+\beta\left[\varphi v_{t+1}\left(a^{\prime}, i, j+1,-x, x\right)+(1-\varphi) v_{t+1}\left(a^{\prime}, i, j+1, x, x\right)\right]\right\}
$$

subject to 


$$
\begin{gathered}
\varphi \in\{0,1\} \\
c+a^{\prime}+\varphi m \leq a(1+r(t))+w_{x}(t) e(j, x), \\
\varphi \cdot a^{\prime} \geq 0 \\
a^{\prime} \geq 0, \text { for } j=J \\
v_{t}(a, i, J+1,-x, x) \equiv 0 . \\
v_{t}(a, i, J+1, x, x) \equiv 0 .
\end{gathered}
$$

Abusing the notation somewhat, denote the optimal decision rules for assets by $a_{t}^{\prime}(z)$, the optimal consumption function by $c_{t}(z)$ and the optimal moving function by $\varphi_{t}(z)$.

Aggregates For aggregation purposes, it is necessary to describe the position of individuals across states. Let $\psi_{t}(B, I ; j, x, y)$ be the mass of people with asset position $a \in B$, type $i \in I$, age $j$, working in location $x$ in period $t$, and born in location $y$. The function (measure) $\psi_{t}$ is defined for all $B$ in $\mathcal{B}$, the class of Borel subsets of $\mathbb{R}$, all Borel subsets $I \subset \mathcal{I}$, all $j \in \mathcal{J}$ and all $x$ and $y$ in $\{\mathcal{R}, \mathcal{P}\}$. For ease of exposition, we derive the function $\psi_{t}$ in Appendix I.

We now illustrate how a number of aggregates and prices can be calculated given $\psi_{t}$. (In Appendix I we present a formal definition of equilibrium.) Given $\psi_{t}$, we can write labor input in location $x$ as

$$
L_{x}(t)=\sum_{j=1}^{J} \psi_{t}(\mathbb{R}, \mathcal{I} ; j, x, x) \cdot e(j, x)+\sum_{j=1}^{J} \int_{\mathbb{R} \times \mathcal{I}}(1-\theta) \cdot e(j,-x) d \psi_{t}(a, i ; j, x,-x)
$$

and population in location $x$ as

$$
N_{x}(t)=\sum_{j=1}^{J} \psi_{t}(\mathbb{R}, \mathcal{I} ; j, x, x)+\sum_{j=1}^{J} \psi_{t}(\mathbb{R}, \mathcal{I} ; j, x,-x)
$$

Similarly, total world's assets at time $t, A(t)$, are given by

$$
A(t)=\sum_{x \in\{\mathcal{R}, \mathcal{P}\}}\left\{\sum_{j=1}^{J} \int_{\mathbb{R} \times \mathcal{I}} a d \psi_{t}(a, i ; j, x, x)+\sum_{j=1}^{J} \int_{\mathbb{R} \times \mathcal{I}} a d \psi_{t}(a, i ; j, x,-x)\right\}
$$


Suppose that we know the past price of land in each location. Then we easily back out the world capital stock from the following equilibrium relation, which expresses the idea that everything is owned by someone:

$$
A(t)=K(t)+p_{\mathcal{R}}(t-1) F_{\mathcal{R}}+p_{\mathcal{P}}(t-1) F_{\mathcal{P}}
$$

Meanwhile, all capital is somewhere, so

$$
K(t)=K_{\mathcal{R}}(t)+K_{\mathcal{P}}(t)
$$

Knowing aggregate labor in each location, we know how the world capital stock is divided; we can solve for $K_{\mathcal{R}}(t)$ and $K_{\mathcal{P}}(t)$ by equating rates of return across locations, i.e. by solving

$$
G_{1}\left(K_{\mathcal{R}}(t), L_{\mathcal{R}}(t), F_{\mathcal{R}} ; A_{\mathcal{R}}\right)=G_{1}\left(K(t)-K_{\mathcal{R}}(t), L_{\mathcal{P}}(t), F_{\mathcal{P}} ; A_{\mathcal{P}}\right)
$$

The above implies that we also know wages rates and rental rates of land; they are given by the respective marginal products. This procedure can be repeated at all points in time. As a result, there is an implied sequence of land prices as these are given by the discounted value of land rental rates. Altogether, these principles constitute the basis for an algorithm to compute equilibria, which we describe in detail in Appendix II.

\subsection{Discussion}

We now elaborate on the implications of a number of features of the model. In the absence of migration, all individuals within a cohort in each location are identical in terms of their earnings and their decisions. Their idiosyncratic psychic cost $(\gamma)$ matters only for the decision to move; given present and future prices, those with relatively high value of $\gamma$ in the poor location will stay at home, whereas those with a relatively low value will move abroad. Note that our assumptions imply that migrants differ from natives as a group for two reasons; the proportional skill loss $\theta$ and because they might be endowed with more or less skills according to the function $e(j, y)$. Migrants of the same cohort are indistinguishable from one another except for their (unobservable) psychic cost $(\gamma)$.

Moreover, migration will be a gradual process. That is, convergence to the new steady state is

not instantaneous because of gradual capital accumulation; more importantly, the movement of people does not end after one period either. There are three distinct but related reasons 
for this. All of them are tied to the life-cycle structure of the economy, and in particular, to the lack of intergenerational altruism.

In the first place, some individuals will be relatively old when the barriers are removed. Since these people do not have many years left to live and they do not care about their children, it is not worthwhile for them to pay a resource moving cost in return for a small period of time with higher earnings. Secondly, individuals cannot borrow to pay for the resource moving cost. Thus, they need time to accumulate assets sufficient to cover it. In addition, since they cannot arrive to the new location with negative assets, the moving decision interferes with their optimal allocation of consumption over the life cycle. Finally, it is the high-portability (i.e. low $\gamma$ ) types that tend to move. Every generation will contain a certain mass of high $\gamma$ types who will not move even if the wage gap is very large. Conversely, each generation will contain a mass of low $\gamma$ types that will move even if the wage gap is not so large.

This gradualness is a desirable property in any dynamic model of labor movements, since gradualness is a consistent feature of migration experiences in the past. For example, about a third of Sweden's population emigrated to the United States during the period 1870-1920. In no year did the emigration rate exceed 1.1 percent. ${ }^{4}$ We exploit later this feature of the model and data to put discipline in the quantitative exercises we carry out (see section 3).

Lastly, we note that when only movements of capital can take place, levels of output per worker can differ in a steady state because of three factors: differences in land stocks per worker, differences in efficiency units of labor, and differences in TFP. More explicitly,

$$
\left(y_{\mathcal{R}} / y_{\mathcal{P}}\right)=\left(A_{\mathcal{R}} / A_{\mathcal{P}}\right)^{(1 /(1-\lambda))} \times\left(\tilde{L}_{\mathcal{R}} / \tilde{L}_{\mathcal{P}}\right)^{\eta /(1-\lambda)} \times\left(z_{\mathcal{R}} / z_{\mathcal{P}}\right)^{(1-\lambda-\eta) /(1-\lambda)}
$$

where $y_{x}$ and $z_{x}$ stand for output per worker and land per worker in location $x$ respectively, and $\tilde{L}_{x}$ are average labor efficiency units per worker. This obviously differs from more standard analyses as differences in land endowments is now one of the determinant of outputper-worker differences. Nevertheless, unless the land share is large, land differences will play at best a secondary role in accounting for the large observed differences in output per worker across countries. To illustrate this point, suppose that both the capital and land shares equal 1/3. This determines that land per worker should be raised only to a factor of $1 / 2$. So in order for differences in land per worker to play a significant role in accounting for

\footnotetext{
${ }^{4}$ Our calculation based on data in Mitchell (1998). See Hatton and Williamson (1998) and O'Rourke and Williamson (1999) for ample evidence on the mass migration process of the 19th century and early 20th century.
} 
measured output-per-worker differences, the land share has to be high and the data have to exhibit a strong positive relationship between land per worker and output per worker. The available evidence supports neither of these features. In Section 3 we review this evidence and conclude that the land share is relative small (about 5-6\%), and that land per worker does not covary systematically with output per worker across countries.

\section{Parameter Values}

In this Section, we assign precise parameter values wherever those values are held constant in all our quantitative exercises. For technology parameters and endowments of labor efficiency units in the rich location, we use U.S. data to pin down their values. This is a compromise given the level of aggregation we consider and in line with existing literature.

We start by assuming that the length of a period is 5 years. Agents enter the model at age 20 and die at the age of 79 years. This implies that the total number of periods a person lives is 12. Lifespans are independent of where individuals are born. This assumption implies that the initial distribution of the labor force (in the absence of migration) coincides with the initial distribution of the population.

We now proceed to use U.S. data to measure the capital and land shares in the aggregate Cobb-Douglas technology. The reader should bear in mind that we assumed that the labor share is the same in both locations, an assumption supported by the findings of Gollin (2002).

We follow Cooley and Prescott (1995) and obtain a share of output accruing to capital and land of about 0.37 , a depreciation rate of capital of about 0.081 and also an implicit rate of return on capital. ${ }^{5}$ After this, it remains to disentangle income from capital and income from land. We do this indirectly by using theory and data on the total value of land as a share of output. Since in a steady state, the marginal product of land equals the interest rate times the price of land, the land share equals $r \times v$, where $v$ is the value of land as a share of total output. Using the interest rate implicitly obtained in the previous step, we obtain a land share of about $0.051 .^{6}$ Together with the previous calculations, this implies a capital

\footnotetext{
${ }^{5}$ The period considered is 1959-1990 and we use the same data sources of Cooley and Prescott (1995). The notion of physical assets include capital equipment, structures, residences, inventories, consumer durables and land.

${ }^{6}$ Our value for the land share is not far from the value of about 0.06 estimated by Caselli and Coleman (2001) for the U.S. non-agricultural sector, which accounts for nearly $98 \%$ of total output.
} 
share of 0.317. Based on these considerations, we set $\lambda=0.317$ and $\eta=0.632$. For some readers, the value of the land share for the poor location might seem low. To understand the quantitative significance of this possibility, we conduct sensitivity analysis where we increase the land share in the poor location; see Section 4.

We assume a CRRA period utility function with parameter $\sigma$. We set $\sigma$ equal to 2 . This value is commonly used in the literature, and is in the range of estimates reviewed by Auerbach and Kotlikoff (1987), Browning, Hansen, and Heckman (1999) and other authors. When land and capital shares are equal across locations, capital to output ratios are the same in each location. Then, for each assumed case of land per worker, we set the discount factor $\beta$ so as to generate a capital to annual output ratio equal to 2.18 , which is consistent with the calibration of the capital share. This implies a world rate of return equal to about $6.7 \%$ on an annual basis.

We parameterize the profile of efficiency units so that

$$
e(j, y)=\tilde{e}(j) \times h_{y}, \quad y \in\{\mathcal{R}, \mathcal{P}\}
$$

The function $\tilde{e}(j)$ is common to both locations, and set equal to the age-profile for U.S. males estimated by Hansen (1993). The parameter $h_{y}$ controls the human capital endowment and shifts the age-efficiency profile in a multiplicative fashion. Later, we will pin down the ratio $h_{\mathcal{R}} / h_{\mathcal{P}}$ using measured differences in educational attainment across the groups of countries that we are considering; see Sections 4 and $5 .^{7}$ We consider two values for the efficiency losses associated with migration: $\theta=0$ and $\theta=0.15$. We note that empirical estimates of earnings losses of immigrants are contained within these bounds. For instance, Borjas (1996) reports earnings losses of migrants of about 15-20\% for the (then) most recent cohort of immigrants from Mexico into the U.S., and about 10-15\% for the rest. Storesletten (1996) finds a value of approximately 15\%. Since arguably some earnings losses are temporary, an upper value of $\theta=0.15$ is reasonable.

We set the stocks of land per worker set equal to 1 in both locations. This assumption is strongly supported by the evidence in Rao (1993), which indicates there is no empirical

7 This specification is consistent with the empirical earnings literature, in which the log of individual earnings is usually represented by a non-linear function of age or experience, plus linear term that depends on schooling years. The coefficient on the linear term is the Mincer return on schooling. Assuming that the the effect of age on earnings is independent of birthplace whereas birthplace affects years of schooling, one obtains the the function $e(j, y)$ in the text. 
association between the stock of land per worker and GDP per worker across countries. For instance: in 1990, arable land per worker was about 1.1 ha in OECD economies and about 0.97 ha in non-OECD countries.

It remains to parameterize the distribution of idiosyncratic utility costs, $\gamma$. We assume that this variable is exponentially distributed with parameter $\rho$, and use implications of the model to make inferences about this parameter. Since our aim is to use the framework to assess the effects of removing barriers to labor mobility, ideally we would like to consider observations pertaining to unrestricted migration experiences. We use for this purpose available evidence from past and recent cases satisfying this criterion, and where sending and receiving countries had income gaps similar to the ones we consider. For example, the emigration rate of citizens of Puerto Rico to the U.S. averaged about $0.8 \%$ in the 1950 's and about $0.5 \%$ in the 1960 's, while output per capita increased from about $21.5 \%$ of that of the United States in 1950 to about $40.1 \%$ in $1975 .{ }^{8}$ In a case directly relevant to this paper, the movement of labor from the 10 new EU members (EU10) into the old 15 member states (EU15) in the first year following accession amounted to about 1.2 percent of the population of EU10. ${ }^{9}$

Prior to the enactment of severe restrictions, the emigration rate of Sweden averaged about $0.7 \%$ per year for the period 1866-1890, while output per capita rose from about $47.4 \%$ of that of the U.S. in 1870 to about $61.4 \%$ in 1890. On the upper bound of estimates is the case of Italy, with emigration rates averaging about $0.8 \%$ for the period 1876-1900, and increasing to about $1.6 \%$ per-year for the period 1888-1913. Output per capita moved in the opposite direction; it went from about $57 \%$ of the U.S in 1876 to $42 \%$ in $1900 .^{10}$

On the basis of this evidence, we set the parameter $\rho$ so that emigration rates in the first 25 years after the removal of barriers average $0.5 \%$ and $1.0 \%$ per year. We do this for each of the cases we consider. In our analysis below, we refer to the first case as the "high psychic costs" case, and to the second one as "low psychic costs" case.

Table 1 summarizes our choices of parameter values. Choices of TFP levels and moving costs are discussed in subsequent sections.

Insert Table 1 here

\footnotetext{
8 Sources: Statistical Abstracts of the United States (various years) and the Penn World Tables.

9 Source: Commission of the European Communities (2006).

10 Sources: Mitchell (1998) and Maddison (1995).
} 


\section{Removing Barriers to Labor Mobility: Steady State Effects}

In this Section, we explore the model framework by considering a number of hypothetical economies and investigate the consequences of removing barriers to labor mobility. To highlight the importance of long-run effects and the role of different forces at work, we compare steady states for the aggregate (world) economy from a given initial distribution of the labor force. In the subsequent sections, we evaluate the effects of removing barriers to labor mobility in economies parameterized to reproduce the European Union and the NAFTA group.

Throughout this section, we assume that the world's labor force is initially divided equally across locations, and consider a set of values for other parameters. In our first group of results, there are no differences in labor quality between natives of poor $(\mathcal{P})$ and rich $(\mathcal{R})$ locations, so that $h_{\mathcal{R}} / h_{\mathcal{P}}=1$. In the second group, labor quality of natives of $\mathcal{R}$ is $50 \%$ higher than labor quality of natives of $\mathcal{P}$, which implies $h_{\mathcal{R}} / h_{\mathcal{P}}=1.5$. We then report results for two values of the moving cost, $m$. The low value is simply equal to zero, while the high value is equal to a value of $1 / 2 \times$ annual GDP per worker of the poor region in the initial situation. $^{11}$

For every case of labor quality differences, we find the corresponding TFP ratio that reproduces an output-per-worker ratio of 2 in the absence of labor movements. Note that when there are no differences in labor quality, all output per worker differences are due to TFP; when $h_{\mathcal{R}} / h_{\mathcal{P}}=1.5$, TFP contributes to output-per-worker differences by a factor of about 1.37 and labor quality contributes a factor of about $1.46 .^{12}$

The key results for steady states are summarized in Table 2. Two striking features emerge; (i) the transition to the new steady state involves a large reallocation of the labor force across locations and (ii) there are large long-run effects on aggregate (world) output. When

\footnotetext{
${ }^{11}$ Note that we do not distinguish steady states according to the distribution of utility costs, as steady states are in fact independent from it. This follows since we assume that the lowest support of the distribution of such costs is zero.

${ }^{12}$ As we discuss below, when labor quality differences are identified using educational attainment data, a value of $h_{\mathcal{R}} / h_{\mathcal{P}}=1.5$ corresponds roughly to the differences in educational attainment within the NAFTA group, between Mexico and the United States, while $h_{\mathcal{R}} / h_{\mathcal{P}}=1$ approximates the case of the enlargement of the European Union. The case of $h_{\mathcal{R}} / h_{\mathcal{P}}=1.5$ also corresponds closely to a partition of the world's labor force between OECD and non-OECD countries; see Klein and Ventura (2006) for details.
} 
$h_{\mathcal{R}} / h_{\mathcal{P}}=1.5$, between $74 \%$ and $98 \%$ of the world's labor force chooses to live and work in the high TFP region in the new steady state, while world output increases between 14.6 and 26.0 percent as a result. When there are no differences in skills of natives of $\mathcal{P}$ and $\mathcal{R}$, nearly the whole world's labor force is located in the high TFP location in the new steady state, and the increase in output amounts to about $27 \%$. These long-run output changes are sizeable by the standards of policy analysis in applied general equilibrium modeling; they take, however, a large number of periods to materialize, a property of the environment that we discuss in detail below.

\section{Insert Table 2}

To understand why even rather modest TFP differences lead to sizeable movements of labor across steady states, note that returns to labor and capital jointly are not very far from constant. The presence of the fixed factor means that returns are diminishing, so that not all capital and land needs to move to the high TFP region in order to equalize returns. But because the land share is relatively small, returns do not diminish very fast. This is perhaps seen most clearly in an environment without moving costs; there, labor moves until wage rates are equalized. Thus in this case, both wages and capital rental rates are equalized, and we have

$$
L_{\mathcal{R}} / L_{\mathcal{P}}=\left(A_{\mathcal{R}} / A_{\mathcal{P}}\right)^{1 /(1-\lambda-\eta)} \times\left(F_{\mathcal{R}} / F_{\mathcal{P}}\right)
$$

This equation says that the ratio of labor input across the two locations is proportional to the TFP ratio raised to a power given by the reciprocal of the land share. In our case, to a value in excess of $1 / 0.06 \approx 16.6$. This simple calculation implies that for TFP levels leading to an output-per-worker ratio of 2 and $h_{\mathcal{R}} / h_{\mathcal{P}}=1.5$, about $98 \%$ of the world population should be located in the rich location in order for wages to be equalized.

To understand the substantial changes in output that accompany the labor movements in Table 2, it is important to note two things. First, at any point in time, the capital-output ratio is equal across locations; this is because capital mobility equalizes rates of return on capital. In this context, that implies that capital "chases" labor; a movement of labor from $\mathcal{P}$ to $\mathcal{R}$ increases the marginal product of capital there, attracting capital as a result. Second, the capital-output ratio is invariant across steady states, so that when labor movements lead to increases in world output, then the world capital stock must increase as well. Thus, the reallocation of capital across locations and capital accumulation act as amplification 
mechanisms; as a result, even modest differences in TFP imply that there are large effects on world output of allowing individuals to move. ${ }^{13}$

It is worth emphasizing that the fact that capital chases labor and is accumulated over time, determine that output per worker and wage rates in the rich location fall by at most $5 \%$ across steady states. This occurs despite the fact that the labor force in the rich location nearly doubles. Note that if the world's stock of capital is fixed and is not reallocated in response to labor movements, output per worker in the rich location would fall by several orders of magnitude more (about 21.5-22.5\%).

Overall, our findings highlight the potential unrealized output gains for the world economy associated with the current division of the labor force, strict barriers to labor mobility and productivity differences as a major determinant of output per-worker differences. Note that about $80 \%$ of the world's labor force is currently located in non-OECD countries, and the output per-worker gap between this group and OECD countries is a factor of about about 4. TFP differences account for a factor of about 2.8 to these differences. ${ }^{14}$ In these circumstances, our analysis strongly suggest that even a relatively small reallocation of the labor force can have large effects on global output in the long run.

The Importance of Capital To assess the quantitative importance of capital movements and capital accumulation for the results in Table 2, we calculate a number of auxiliary statistics presented in Table 3. The Table shows (i) the increase in world output due exclusively to movements of labor (i.e for a given world capital stock and a given division between locations); (ii) the increase in world output due to the movement of labor, for the old capital stock under its new division; (iii) the total increase in world output. Under this decomposition, at most $53 \%(7.8 / 14.6)$ of the increase in world output is accounted for by labor movements alone. This implies that the residual increase, at least $47 \%$, corresponds to changes in the stock of capital and its allocation across locations. The implication is that abstracting from capital accumulation, and its division across countries, can lead to a misleading picture of the aggregate effects of barriers to labor mobility.

\section{Insert Table 3}

\footnotetext{
${ }^{13}$ In Klein and Ventura (2006) we explore the steady state effects of labor movements in various scenarios. We prove that labor movements in the context of TFP differences increase in the world's capital stock, and that a higher fraction of the capital stock concentrates in the high TFP region as a result.

14 Our calculations based on data from the Penn World Tables (6.1) and Barro and Lee (2000).
} 
The Importance of Land Since the assumption of a common land share may suggest that the value of the land share is relatively low for the low TFP location, we investigate the effects of different values of this parameter across locations. One key motivation for this exercise are observations that indicate that the share of land in total output varies inversely with the level of development, and that cross-country estimates of the land share in agriculture are in the range of $0.15-0.20 .^{15}$

To highlight the importance of the land share we conduct an experiment in an extreme case: we leave the labor share in both locations as before (in consistency with data), but reduce the capital share in the poor location only so that the land share triples in relation to the benchmark case. This implies $\lambda_{\mathcal{R}}=0.317$ and $\lambda_{\mathcal{P}}=0.215$, with a corresponding land share in the low TFP location of 0.153. As previously, we calculate for each value of assumed labor quality the TFP value that reproduce an output per worker ratio of 2 .

Bounds on output changes are given by the cases of $m=\theta=0$ and $h_{\mathcal{R}} / h_{\mathcal{P}}=1.0$ (i.e. no moving costs, no efficiency losses, no difference in labor quality of natives), and by $m=0$, $\theta=0.15$ and $h_{\mathcal{R}} / h_{\mathcal{P}}=1.5$ (i.e. no moving costs, efficiency losses of $15 \%$ and $50 \%$ higher labor quality of natives of the rich location). The output effects are now smaller; $23.0 \%$ in the first case and $13.7 \%$ in the second case, while these output changes amount to $26.6 \%$ and $14.6 \%$ under the benchmark calibration. This is not surprising; intuitively, as the returns to labor and capital jointly diminish faster, a smaller reallocation of labor is required to make individuals indifferent in terms of moving decisions. Thus, smaller movements of labor take place, which in turn lead to a smaller increase in world output. Quantitatively however, the effects on world output are still rather non-trivial. We conclude that uncertainty about the importance of the land share is likely to be of second order importance in assessing the long-run effects of labor mobility.

\section{Removing Barriers to Labor Mobility: The Euro- pean Union and NAFTA Cases}

We now use the model to study the effects of labor mobility in two cases. The first case pertains to the enlargement of the European Union that started in 2004. The second case is the (hypothetical) creation of a common labor market within the NAFTA bloc. Both cases

\footnotetext{
${ }^{15}$ See Mundlak (2001) for a review of evidence on land shares in agriculture.
} 
constitute major policy shifts, and are of special interest beyond their empirical relevance.

The exercises we conduct in all cases is the following: departing from a steady state in which individuals are not allowed to move, we suddenly and unexpectedly remove legal barriers to migration. We restrict our attention to the transitional dynamics that ensue under the (realistic) portfolio assumption that in the initial steady state, all of the land stock in each location is held exclusively by residents of that location. To assess properly the exercises we conduct, is important to keep in mind that we assume that the relative levels of TFP are constant along the transition path. Beyond simplifying the computation of transitional dynamics, this assumption serves to highlight the aggregate effects driven by labor movements along transition paths.

Parameterization From May 2004, citizens from Cyprus, the Czech Republic, Estonia, Hungary, Lithuania, Latvia, Malta, Poland, Slovakia and Slovenia are allowed to work anywhere in the European Economic Area. ${ }^{16}$ To assess the effects of this policy shift within our model, we need to pin down the relative level of skills between old and new members of the Union, as well as the distribution of the labor force between locations. From the Penn World Tables, using labor force weights, we calculate that the ratio of output per worker of the old members of the Union relative to the new ones was 2.17 in 2000 , so $y_{\mathcal{R}} / y_{\mathcal{P}}=2.17$ is now our target in the absence of labor movements. Using the same data, we set the initial condition for the distribution of the labor force: $83.2 \%$ in old member countries, and $16.8 \%$ in the new member countries.

We pin down the ratio $h_{\mathcal{R}} / h_{\mathcal{P}}$ using measured differences in educational attainment across the two groups of countries. From Barro and Lee (2000), the population-weighted average years of education (among those in the population 15 years or older), is quite similar between the two groups: 9.5 for new members and about 8.7 for old members. We view this as evidence that there are no significant differences in labor quality between natives of "old" and "new" Europe. If anything, new Europeans are more educated than old Europeans. We take a conservative approach and set $h_{\mathcal{R}} / h_{\mathcal{P}}=1.0$. Note that this parameterization attributes all initial differences in output per worker to productivity differences (TFP). ${ }^{17}$

\footnotetext{
16 The European Economic Area consists of the European Union, Iceland, Liechtenstein and Norway. The only caveat regarding the starting date is a seven-year optional moratorium on labor mobility that some old member countries are making use of.

${ }^{17}$ It is worth pointing out that the available evidence so far on the enlargement of the European Union is broadly consistent with the past experiences that we base our parameterization on. For 2004, the emigration
} 
For the creation of a common labor market within NAFTA, we divide the bloc into a rich location (U.S. plus Canada) and a relatively poor location (Mexico). From the Penn World Tables, using labor force weights, we calculate that the ratio of output per worker of U.S. plus Canada to Mexico was 2.57 in 2000, and the initial condition for the distribution of the labor force is of about $82.0 \%$ in Canada plus the United States, and about $18.0 \%$ in Mexico. Using the same data and definitions as above, we obtain substantial differences in educational attainment in this case: workers in Mexico have about 7.2 years of education while workers in Canada plus the U.S. have about 12. This implies $h_{\mathcal{R}} / h_{\mathcal{P}}=1.63$ under a Mincerian rate of return of $10 \%$.

Overall, it follows that the case of NAFTA has important similarities and differences with the European case. On the one hand, note that the initial distribution of the labor force is quite similar: $83.2 \%$ in "Old Europe" and $82.0 \%$ in the U.S. plus Canada, while it is about $16.8 \%$ in "New Europe" and $18.0 \%$ in Mexico. On the other hand, we attribute all initial differences in output per worker to productivity differences in the European case, while given observed differences in educational attainment, differences in productivity contribute by a factor of about 1.7 to differences in output per worker in the NAFTA case (out of a total difference of a factor of nearly 2.6).

For both cases, we report results for a single value of the moving cost $m$, which we set to 0.5 times annual GDP per worker in the poor location. Below, we explore the sensitivity of the results to this choice.

Findings Tables 4 and 5 display the results from the removal of barriers in the European Union and NAFTA cases. After 10 years, aggregate output changes are not large; they range from about $0.2 \%$ to $0.6 \%$ in the European case and from $0.1 \%$ to $0.4 \%$ in the NAFTA case, depending on the presence of large or small psychic costs and the magnitude of efficiency losses. After 50 years, output changes much larger; they range from about $1.7 \%$ to $4.5 \%$ in the case of Europe, and from about $1.3 \%$ to $3.0 \%$ in the NAFTA case. In terms of the distribution of the population, after 50 years the population of the rich locations in Europe and North America increase by about 5-9\%.

Insert Tables 4 and 5 .

rate from the ten new member states into the EU-15 amounted to about 1.1\%. Source: Commission of the European Communities (2006). 
In the long run, output changes are of about $8 \%$ in the European case and of about $10.5 \%$ in the NAFTA case. In other words, there are large output gains on the table, but they take several periods to materialize. Notice here that, quantitatively, the speed of the transition stands in sharp contrast with the properties of standard growth models, which predict rapid convergence to the steady state with a half-life of about 5 years for a capital share around $1 / 3 .^{18}$ This is related to gradual movements of the labor force; we elaborate further on this property below. Note also that, not surprisingly, output gains in the short run are the largest when there are no efficiency losses associated with labor movements.

The tables show that short run output gains are larger in Europe. This occurs as TFP accounts for a larger fraction of the initial difference in output per-worker in Europe than in the NAFTA case. Hence, given a similar initial distribution of the labor force, comparable emigration rates in the first 25 years generate in the short run a larger effect on total output in Europe than in North America. In the long run, nevertheless, output gains can be larger in the case of NAFTA than in the case of Europe. The reason for this is simply that differences in the the quality of labor vanish in the long run as those born in the new (rich) location are endowed with the human capital (labor quality) prevailing there. Thus, for comparable population movements (taking place under $\theta=0$ ), the resulting output gains are larger in the NAFTA case than in the Europe case. This is consistent with the steady-state results presented in Table 2.

The economic forces at work that account for the transition patterns are simple. As we mentioned before, finite lives, resource moving costs and idiosyncratic psychic moving costs, in conjunction with borrowing constraints, lead to gradualness in population movements. That is, only a fraction of the population of the relatively poor location moves at any given point in time. This process continues for several periods, as there are always young individuals in the poor location who are born with relatively low psychic moving costs who move and those with high psychic moving costs who don't. In addition, the size of the labor input grows over time in the rich location (beyond the direct contribution of migrants) as all newborns there are born with the level of human capital of natives of that location. More labor in the high TFP location determines that the marginal product of capital increases. This in turn triggers both accumulation of capital, and an increasing share that the high TFP location gets of the world's capital stock. The net results are gradual movements of population, and gradual increases in world's capital and output that are summarized the

\footnotetext{
${ }^{18}$ See Barro and Sala-i-Martin (1999), chapter 2, for a textbook discussion of speed of convergence in the one sector neoclassical growth model.
} 
tables. Finally, it is worth mentioning that these changes lead in turn to a relatively smooth pattern for rates of return. ${ }^{19}$

Welfare We now report the welfare consequences of lifting barriers to migration in our experiments. We proceed as follows. For each type $i$, we calculate the percentage increase in consumption that is required in each period in order to make individuals indifferent between a world without migration barriers, and the status quo. The average of this consumption compensation across individuals of a given cohort is the welfare gain that we report in Tables 6 and 7 . Notice that these welfare gains are averages over many individuals, not all of whom actually move. To understand the results reported in the tables, recall that individuals live for 12 periods. Then, generation 1 is the generation whose last period of life takes place when migration barriers are lifted, say $t_{0}$. Similarly, generation 12 is the one that is born at date $t_{0}$. Generation 24 corresponds to those individuals who are born during the transition path, 12 periods (60 years) after the hypothetical removal of the barriers.

\section{Insert Tables 6 and 7}

A few of properties of the results are worth noticing. First, observe that the oldest individuals in the rich (high TFP) location gain when barriers are removed, while the opposite occurs in the poor (low TFP) location. This is straightforward: as natives of the rich location hold all land in this location and the oldest individuals have mostly asset income, lifting barriers to the movement of labor will lead to gains for these if the value of their land increases. This is precisely what occurs as the increase in the labor input in the rich location increases the marginal product of land over time, which in turn leads to an upward jump in the price of land in the rich location at $t_{0}$. Of course, the reverse happens in the poor location.

Second, individuals born at $t_{0}$ gain in the poor location and lose in the rich location, and the smaller are idiosyncratic moving costs on average, the greater the welfare gain (loss) for natives of the poor (rich) location. Notice, in particular, that individuals in the poor location gain substantially on average even when only a small fraction of them eventually moves to the rich location. This is accounted for by the fact that prices change in a favorable direction for newborns in the poor location; wage rates there increase over time because of diminishing returns to labor and capital jointly.

\footnotetext{
19 The results indicate that the rate of return to capital is never more than one half of a percentage point above its steady state value in annual terms, despite the magnitude of output changes and labor movements.
} 
Overall, the removal of barriers to labor mobility has non-trivial consequences for welfare, but these consequences differ substantially across locations and cohorts. At the date when restrictions are removed $\left(t=t_{0}\right)$ old and middle-aged rich location natives gain, while young rich location natives lose. The losses of the youngest can be sizeable; in the European case for instance, their losses can go up to $0.57 \%$ of their consumption. The average gains, however, of the youngest in the poor location are proportionally much larger in magnitude; for the same case, they gain from $2.7 \%$ to $6.2 \%$.

Quantitatively, our analysis indicates that there are sizeable gains from labor mobility available, both in terms of output and welfare. The source of the gains are the (large) TFP differences across locations that are amplified by capital movements and capital accumulation. Our results suggest that the maximum welfare losses for those in the rich location are rather small in comparison to the size of potential welfare gains. The amplification role of capital movements and accumulation is key for these findings; without a role for capital, wage rates in the rich location would fall by a much larger amount and young individuals there would suffer substantially.

Discussion We now provide some perspective on our findings by comparing them with the results from other quantitative exercises in the literature. Specifically, we focus on the effects of tariff reductions, liberalization of capital flows and reduction of capital income taxes.

The effects of trade reform, as measured by static general equilibrium models, are much smaller than the output gains that we report. See for example, de Melo and Tarr (1992), and Alvarez and Lucas (2006), for a recent analysis in the context of the Eaton-Kortum model of trade. ${ }^{20}$ Dynamic features are required to generate output gains of the same order of magnitude as the ones we report in the medium run (see Table 4). In their study of the role of tariffs for the Great Depression in the United States, Crucini and Kahn (2003) find that cutting tariffs from 60 percent to 10 percent at home and abroad would increase output by $5.1 \%$; when no intermediate inputs are considered, the change in output is substantially smaller $(3.0 \%)$. The effects of liberalizing international capital markets are an order of magnitude lower still. Gourinchas and Jeanne (2006) find that the welfare gains from financial integration in an infinitely-lived environment are about $1.2 \%$ for non-OECD countries, and

\footnotetext{
${ }^{20}$ Alvarez and Lucas (2006), Table 2, find that the worldwide cost of current tariffs, relative to a hypothetical no-tariff situation, amounts to about $0.5 \%$ of world GDP.
} 
about $0.8 \%$ for Latin America. ${ }^{21}$ These welfare gains should be compared to the much larger welfare gains of (finitely-lived) natives of poor locations reported in Tables 6 and 7 . On the other hand, Gourinchas and Jeanne (2006) find that the welfare gains from increasing productivity in poor countries are much larger; the reason for this, of course, is that productivity differences are the key determinant of cross-country income differences. Our findings are consistent with theirs. Indeed, barriers to labor mobility can be thought of as barriers to the concentration of capital and labor in high productivity locations. As a result, a removal of barriers to labor mobility amounts to an effective increases in productivity (TFP) for the aggregate (world) economy.

Finally, we compare the effects of barriers to labor mobility with the effects of capital income taxation. We introduce a capital income tax in our framework and ask: How big would it have to be for its elimination to generate output gains similar to the ones emerging from the removal of barriers to labor mobility? Addressing this question puts our results in the context of the large quantitative-theoretical literature on the effects on output, capital accumulation and welfare of eliminating/reforming capital income taxation (see Lucas (1990) for a discussion and review). The exercise we conduct is to compare steady states with and without worldwide capital income taxes, when the proceeds from these are returned lumpsum to individuals. We find that capital income tax rates ranging from about $40 \%$ to about $45 \%$ are needed in order for their elimination to generate the long-run output gains resulting from the removal of labor mobility barriers. Therefore, a perspective emerging from these exercises is that for the case of EU enlargement and NAFTA deepening, the presence of labor mobility barriers is equivalent to substantial capital income tax rates; not far, in fact, from the observed ones. Recent estimates indicate that tax rates on capital income in the United States averaged $39.5 \%$ for 1990-2000, whereas these rates amounted to an average of $47.5 \%$ in the European Union and about $46.3 \%$ in the OECD. ${ }^{22}$

From these results, given the magnitude of the potential welfare gains for those who gain, and the heterogeneity in terms of age and birthplace at $t=t_{0}$, it is natural to ask whether it is possible for those who lose to compensate the winners so as to prevent the removal of barriers. In other words, as of $t_{0}$, would the losers be prepared to pay the gainers so as to persuade them to keep the barriers in place? While we do not address this issue, this

\footnotetext{
${ }^{21}$ Caselli and Feyrer (2005) also report relatively small output gains from an efficient reallocation of capital across locations.

22 These estimates come from Carey and Rabesona (2002), Table 2, who improved upon the procedure developed by Mendoza, Razin, and Tesar (1994).
} 
is a fundamental question in light of what is potentially available. The question becomes of first-order importance if the world as a whole is taking into account. This follows since output and welfare gains increase with TFP differences, differences in TFP are large, and most of the world labor force is located in low TFP locations.

\subsection{The Role of Resource Moving Costs and Borrowing Con- straints}

In this Section we briefly explore the significance of two features of the model: the assumption that migrants cannot leave with negative assets (the borrowing constraint) and the assumption that migrants have to pay a fee amounting to half of initial annual GDP/worker in the poor location (the resource moving cost). For the sake of brevity, we will consider the case of North America only, under the assumption that there are skill losses associated with migration $(\theta=0.15)$ and that psychic costs are low, i.e. they are distributed in such a way as to generate an average emigration rate of 1 percent per year during the first 25 years when both the borrowing constraint and the resource moving cost are present. This distribution is kept fixed when we remove these features.

The exercise we conduct is to remove sequentially each feature, and lastly, both of them at the same time. As can be seen in Table 8, the borrowing constraint turns out to be quantitatively more significant than the resource moving cost. Whether the borrowing constraint is present or not, removing the resource moving cost has only a small effect on output gains and population movements; its additional impact on world output is never in excess of one percentage point after 25 years. The borrowing constraint, however, does have a noticeable impact; for example, in the presence of the resource moving cost, the output gain after 25 years is more than twice as large when the borrowing constraint is absent as it is when it is present (1.6 versus 0.7 percent). In the absence of the resource moving cost, it is $80 \%$ larger (1.8 versus 1.0 percent). Notice also that there is an interaction effect: each feature is more important in the presence of the other.

Table 8 also shows that the significance of both of these features diminishes over time. It is not hard to give reasons for this. In the case of the resource moving cost, its importance shrinks in relative terms as world output per worker grows but the resource moving cost does not. In the case of the borrowing constraint, one reason for why the importance of this feature diminishes over time is that it matters more for those born before the barriers to 
labor mobility are removed, since they have not had a chance to prepare for migration by saving. Such people exist until 55 years after the removal of barriers, but not thereafter.

\section{Concluding Remarks}

The analysis in this paper leads us to conclude that barriers to labor mobility are a policy issue of first-order importance. The significance of these barriers are the result of disparities between rich and poor countries, and the fact that these disparities appear mostly to be attributable to differences in productivity.

Of course, the cases we consider in this paper are illustrations of this point on a limited scale. Removing barriers to labor mobility on a global scale (e.g. opening up OECD labor markets to workers from outside the OECD) would likely have much larger effects on output and welfare than the numbers we report in this paper. Indeed, a powerful case can be made that regulation of labor mobility is one of the most severe distortions facing the world today. Taking the results of the applied general equilibrium literature seriously, hardly any policy reform at a global scale, either drastic trade liberalization or worldwide tax reforms, would deliver comparable output gains. In light of the large potential efficiency gains from lifting/easing existing barriers, to defend them on efficiency grounds, one would need to come up with some very powerful arguments indeed. Of course arguments to restrict labor mobility do exist (e.g. congestion of some public goods, burden on the welfare state), but it seems doubtful whether they are powerful enough to make a case for the severity of current restrictions.

Moreover, our analysis has obvious consequences for the analysis of within-country barriers to labor movements. China, and to a lesser extent Russia, is a striking example of this phenomenon. A large fraction of the Chinese labor force is still legally prevented from moving from rural areas to cities. This occurs despite large differences in output per capita and wage rates. Our findings suggest that the output and productivity gains resulting from further liberalization in China are likely to be substantial.

Our analysis illustrates the need to design and study the effects of alternative migration/transfer policies in dynamic frameworks. We found that while the removal of migration barriers generates long-run output gains that are sizeable as well, there are winners and losers in the short run. An open challenge is then how to capture potentially large output and welfare 
gains while making nobody worse off. We leave this and related issues for future research.

We conclude by noting that this paper takes TFP differences as given. We do not take a stand here on the origins of these differences; rather, we take the view that our results are robust to several possible origins. In particular, it should be clear that our results remain valid if TFP differences arise from barriers to technology adoption, poor protection of property rights, inefficient regulation or, generally speaking, bad institutions. Although an implication of our framework is simply that moving institutions to the people is better than moving people to the institutions, we can still establish that large unrealized gains are on the table if people are allowed to move to more productive locations, whenever these differences are unchanged over time. These conclusions become specially relevant as we find that productivity differences of only a moderate size lead to substantial effects on output and labor movements associated with the removal of migration barriers.

However, suppose measured TFP is effectively unmeasured human capital. Then our results would indeed be invalidated. But there are very good reasons to think that this is not the case. Hendricks (2002) provides evidence directly pertinent to this point, using data on the earnings of immigrants in the United States. He shows that unmeasured differences in human capital between natives and immigrants (i.e. differences not reflected in years of schooling) generate only small differences in earnings. The implication is that differences in unmeasured human capital across natives of different countries can only account for a small fraction of cross-country income differences. This leaves us with TFP as the main factor in accounting for cross-country income differences, as Prescott (1998) and many others concluded as well. 


\section{Appendix I: Equilibrium Definition}

Let $\psi_{t}(B, I ; j, x, y)$ be the mass of people with asset position $a \in B$, type $i \in \mathcal{I}$, age $j$ currently in location $x$ in period $t$ and born in location $y$. The function (measure) $\psi_{t}$ is defined for all $B$ in $\mathcal{B}$, the class of Borel subsets of $\mathbb{R}$, all Borel subsets $I \subset \mathcal{I}$, all $j \in \mathcal{J}$ and all $x$ and $y$ in $\{\mathcal{R}, \mathcal{P}\}$. The dynamic evolution of $\psi_{t}$ is as follows.

We begin with the newborns; they arrive according to

$$
\psi_{t+1}(B, I ; 1, x, y)=\left\{\begin{array}{l}
\frac{N_{x}(t)}{J} \int_{I} \alpha(i) d i \text { if } 0 \in B \text { and } x=y \\
0 \text { otherwise. }
\end{array}\right.
$$

where $N_{x}(t)$ stands for the population of location $x$ at $t .^{23}$ Notice that we take for granted that a newborn did not move in the previous period.

Since everyone dies at age $J$, we have

$$
\psi_{t+1}(B, I ; J+1, x, y)=0
$$

For $1<j \leq J, \psi$ obeys the following recursions. For the case $x^{\prime}=x=y$, we have

$$
\begin{aligned}
& \psi_{t+1}(B, I, j, x, x)= \\
& \int_{\mathbb{R} \times I}\left(1-\varphi_{t}(a, i, j-1, x, x)\right) I\left\{a_{t}^{\prime}(a, i, j-1, x, x) \in B\right\} d \psi_{t}(a, i ; j-1, x, x)
\end{aligned}
$$

In words, the mass of individuals in the next period located at $x$ who were born also at $x$ are those who were born at $x$ and located at $x$ the current period and decided not to move.

In similar fashion, the number of individuals at location $x$ next period but who were not born at $x$ includes (i) those who were born and are located at $-x$ in the current period and decided to move; (ii) those who were born at $-x$ and are already at location $x$ in the current period. Formally,

23 Thus the number of newborns in a region is proportional to the total number of people in that region. Alternatively, one could assume that the number of newborns in a region is proportional to the number of people in a certain age range. 


$$
\begin{aligned}
& \psi_{t+1}(B, I ; j, x,-x)= \\
& \underbrace{\int_{\mathbb{R} \times I} \varphi_{t}(a, i, j-1,-x,-x) I\left\{a_{t}^{\prime}(a, i, j-1,-x,-x) \in B\right\} d \psi_{t}(a, i ; j-1,-x,-x)}_{\text {Natives of }-x \text { who arrive to } x \text { at } t+1}+ \\
& \underbrace{\int_{\mathbb{R} \times I} I\left\{a_{t}^{\prime}(a, i, j-1, x,-x) \in B\right\} d \psi_{t}(a, i ; j-1, x,-x)}_{\text {Past arrivals from }-x}
\end{aligned}
$$

We are now ready to provide an equilibrium definition.

Equilibrium An equilibrium consists of a sequence of value functions $v_{t}(z)$, optimal decision rules $a_{t}^{\prime}(z), c_{t}(z)$ and $\varphi_{t}(z)$, aggregate variables $K_{x}(t)$ and $L_{x}(t)$ for $x=\{\mathcal{R}, \mathcal{P}\}$, a measure $\psi_{t}$ and prices $r_{x}^{k}(t), w_{x}(t), r_{x}^{f}(t)$ and $p_{x}(t)$ for $x=\{\mathcal{R}, \mathcal{P}\}$ such that

1. The optimal decision rules $a_{t}^{\prime}(z), c_{t}(z)$ and $\varphi_{t}(z)$ solve the individuals' dynamic problem and $v_{t}(z)$ are the resulting value functions.

2. Markets are competitive:

$$
\begin{gathered}
r_{x}^{k}(t)=G_{1}\left(K_{x}(t), L_{x}(t), F_{x} ; A_{x}\right)-\delta, \\
w_{x}(t)=G_{2}\left(K_{x}(t), L_{x}(t), F_{x} ; A_{x}\right),
\end{gathered}
$$

and

$$
R_{x}^{f}(t)=G_{3}\left(K_{x}(t), L_{x}(t), F_{x} ; A_{x}\right)
$$

for all $x=\{\mathcal{R}, \mathcal{P}\}$.

3. There are no arbitrage opportunities. This implies that all assets earn a common rate of return $r(t)$; specifically,

$$
r(t)=r_{x}^{k}(t)
$$

and

$$
1+r(t)=\frac{p_{x}(t)+R_{x}^{f}(t)}{p_{x}(t-1)}
$$

for all $x \in\{\mathcal{R}, \mathcal{P}\}$ 
4. Markets clear so that

$$
L_{x}(t)=\sum_{j=1}^{J} \psi_{t}(\mathbb{R}, \mathcal{I} ; j, x, x) \cdot e(j, x)+\sum_{j=1}^{J} \int_{\mathbb{R} \times \mathcal{I}}(1-\theta) \cdot e(j,-x) d \psi_{t}(a, i ; j, x,-x)
$$

for all $x=\{\mathcal{R}, \mathcal{P}\}$ and

$$
\begin{gathered}
\sum_{x \in\{\mathcal{R}, \mathcal{P}\}} \sum_{j=1}^{J}\left[\int_{\mathbb{R} \times \mathcal{I}} a d \psi_{t}(a ; i, j, x, x)+\int_{\mathbb{R} \times \mathcal{I}} a d \psi_{t}(a ; i, j, x,-x)\right]=K(t+1)+p_{\mathcal{R}}(t) F_{\mathcal{R}}+p_{\mathcal{P}}(t) F_{\mathcal{P}} \\
K(t)=K_{\mathcal{R}}(t)+K_{\mathcal{P}}(t)
\end{gathered}
$$

5. The world resource constraint is satisfied:

$$
\begin{gathered}
G\left(K_{\mathcal{R}}(t), L_{\mathcal{R}}(t), F_{\mathcal{R}} ; A_{\mathcal{R}}\right)+G\left(K_{\mathcal{P}}(t), L_{\mathcal{P}}(t), F_{\mathcal{P}} ; A_{\mathcal{P}}\right)+(1-\delta) K(t)= \\
\sum_{j=1}^{J} \sum_{x \in\{\mathcal{R}, \mathcal{P}\}}\left[\int_{\mathbb{R} \times \mathcal{I}} c(a ; i, j, x, x) d \psi_{t}(a ; i, j, x, x)+\int_{\mathbb{R} \times \mathcal{I}} c(a ; i, j, x,-x) d \psi_{t}(a ; i, j, x,-x)\right]+ \\
K(t+1)+\sum_{j=1}^{J} \sum_{x \in\{\mathcal{R}, \mathcal{P}\}} \int_{\mathbb{R} \times \mathcal{I}} \varphi_{t}(a ; i, j, x, x) m d \psi_{t}(a ; i, j, x, x)
\end{gathered}
$$

6. Measure of agents over types $\psi_{t}$ is generated as in the text. 


\section{Appendix II: Computation}

Below we describe how to compute equilibria in the model economy we study. We divide our discussion in two parts: (i) computation of steady states; (ii) computation of transitions between steady states.

\section{II.1 Steady States}

There are two cases we need to consider. The first one pertains to the case in which no labor mobility is allowed (or equivalently, mobility costs are arbitrarly high). Hence, given $N_{\mathcal{R}}$ people in location $\mathcal{R}$ and $N-N_{\mathcal{R}}$ people in location $\mathcal{P}$, we need to calculate the steady state for the 'world' economy with perfect (costless) mobility of capital.

The algorithm is as follows:

1. Guess steady state world capital, $K^{*}$.

2. Obtain aggregate labor input in both locations (this can be done since we know that newborns are in proportion to total population and that type does not change as people age).

3. Obtain capital in both locations by solving

$$
G_{1}\left(K^{*}-K_{\mathcal{R}}^{*}, L_{\mathcal{P}}^{*}, F_{\mathcal{P}} ; A_{\mathcal{P}}\right)=G_{1}\left(K_{\mathcal{R}}^{*}, L_{\mathcal{R}}^{*}, F_{\mathcal{R}} ; A_{\mathcal{R}}\right)
$$

4. Calculate wage rates in both locations and the rate of return on assets $\left(w_{\mathcal{R}}^{*}, w_{\mathcal{P}}^{*}, r^{*}\right)$. Calculate the steady state price of land in both locations.

5. Solve for individual decisions.

6. Obtain the implied steady state measure $\psi^{*}$. Do this simply by following a single generation through life.

7. From $\psi$, find the value of implied world assets $A$. Also, find the value of world assets by adding world capital to the value of land.

8. If the values above are consistent with one another and with the initial guess of world capital, STOP. Otherwise, update. 
The second case to consider pertains to the situation in which people could have moved across locations in the past. Given the presence of the moving cost, there can be a continuum of distributions of people across locations (e.g. $N_{\mathcal{P}}, N-N_{\mathcal{P}}$ ) that are consistent with a steady state. Formally, in terms of people residing in the poor location, let the interval $D=\left[N_{\mathcal{P}}^{-}, N_{\mathcal{P}}^{+}\right]$be the interval that contains the distributions of population consistent with a steady state.

We will search for the upper bound of $D$, the population level $N_{\mathcal{P}}^{+}$. This is the population level of the poor location that is part of a steady state and generates the highest wage gap in favor of the rich location. Notice that the population level of the poor location that generates equal wages in both locations, $\tilde{N}_{\mathcal{P}}$, is necessarily a member of $D$. That is, $\tilde{N}_{\mathcal{P}} \in D$. The algorithm described below bisects the interval $\left[\tilde{N}_{\mathcal{P}}, N\right]$ in order to find $N_{\mathcal{P}}^{+}$

We proceed as follows:

1. Find $\tilde{N}_{\mathcal{P}}$. Do this by searching across steady states without migration for the steady state with $w_{\mathcal{R}}=w_{\mathcal{P}}$. Notice that nobody will attempt to migrate in this situation!

2. Let $N_{\mathcal{P}}^{L}=\tilde{N}_{\mathcal{P}}$ (lower bound of bisection interval). Let $N_{\mathcal{P}}^{H}=N$ (upper bound of bisection interval).

3. Guess $N_{\mathcal{P}}^{0} \in\left[N_{\mathcal{P}}^{L}, N_{\mathcal{P}}^{H}\right]$. Solve for an open economy steady state under the assumption that nobody moves (moving costs are prohibitively expensive).

4. Check whether or not individuals would move, given $m<+\infty$. If somebody moves, then $N_{\mathcal{P}}^{H}=N_{\mathcal{P}}^{0}$ and go back to step 3. Else, if nobody wants to move, then $N_{\mathcal{P}}^{L}=N_{\mathcal{P}}^{0}$ and go back to step 3 .

5. Iterate until convergence.

\section{II.2 Transitions Between Steady States}

Consider a transition induced by the unexpected removal of migration barriers. We calculate the steady states associated with for given initial conditions in terms of the distribution of population, and when people have migrated in the past. Then, we obtain values of world capital and in each location, labor in both locations as well as rental and land prices. ${ }^{24}$ We

${ }^{24}$ Notice that land prices in a steady state are given simply by $p_{x}^{*}=\frac{R_{x}^{*}}{r^{*}}$ 
specify terminal time $T$, so that the economy hits the new steady state after $T$ periods. More precisely, at time $t=T$ the relevant statistics of the economy are those pertaining to the new steady state.

We follow the following steps.

1. Guess sequences $\{K(t)\}_{t=1}^{T}$ and $\left\{L_{x}(t)\right\}_{t=1}^{T}, x \in\{\mathcal{R}, \mathcal{P}\}$.

2. Obtain capital in each location by equating marginal products of capital. Find $\left\{R_{x}(t)\right\}_{t=1}^{T}$, $\left\{w_{x}(t)\right\}_{t=1}^{T}$ and $\{r(t)\}_{t=1}^{T}$ by calculating marginal products. Hence calculate land prices

$$
\left\{\begin{aligned}
p_{x}(T) & =p_{x}^{*} \\
p_{x}(t-1) & =\frac{p_{x}(t)+R_{x}(t)}{1+r(t)}
\end{aligned}\right.
$$

for $t=T-1, T-2, \ldots 1$.

3. Solve for individual decisions.

4. Aggregate individual decisions and obtain implied sequences $\left\{K^{\prime}(t)\right\}_{t=1}^{T}$ and $\left\{L_{x}^{\prime}(t)\right\}_{t=1}^{T}$. If these sequences are sufficiently close to those guessed, STOP. If not, update and return to step 2 . 
Table 1: Parameter Values

\begin{tabular}{|l|r|}
\hline Capital Share $(\lambda)$ & 0.317 \\
Labor Share $(\eta)$ & 0.632 \\
Land Share $(1-\lambda-\eta)$ & 0.051 \\
Depreciation Rate $(\delta)$ & 0.081 \\
Intertemporal Substitution $(1 / \sigma)$ & 0.5 \\
Annual Discount Factor $(\beta)$ & 0.976 \\
Land Per Worker $\{\mathcal{R}, \mathcal{P}\}$ & $\{1.0,1.0\}$ \\
Loss of Efficiency Units $(\tau)$ & $\{0.0,0.15\}$ \\
\hline
\end{tabular}


Table 2: Steady State Effects on Key Variables

\begin{tabular}{|c|c|c|c|c|}
\hline Economy & $\begin{array}{c}\text { World } \\
\text { Output } \\
\text { (\% change) }\end{array}$ & $\begin{array}{c}\text { World } \\
\text { Capital } \\
\text { (\% change) } \\
\end{array}$ & $\begin{array}{c}\text { Population } \\
\mathcal{R} \\
(\%) \\
\end{array}$ & $\begin{array}{c}\text { Output } \\
\text { Per Worker }(\mathcal{R}) \\
(\% \text { change })\end{array}$ \\
\hline \multicolumn{5}{|l|}{ Case I: No Moving Costs } \\
\hline Equal Human Capital $h_{\mathcal{R}} / h_{\mathcal{P}}=1.0$ & & & & \\
\hline$\overline{\text { No skill losses }(\theta=0.0)}$ & 26.6 & 26.6 & $>99$ & -5.0 \\
\hline Skill losses $(\theta=0.15)$ & 26.6 & 26.6 & $>99$ & -5.0 \\
\hline \multicolumn{5}{|l|}{ Different Human Capital $h_{\mathcal{R}} / h_{\mathcal{P}}=1.5$} \\
\hline No skill losses $(\theta=0.0)$ & 26.0 & 26.0 & 98 & -4.9 \\
\hline Skill losses $(\theta=0.15)$ & 19.5 & 19.5 & 84 & -3.8 \\
\hline \multicolumn{5}{|l|}{$\begin{array}{l}\text { Case II: Moving Costs }=(1 / 2) \\
\text { GDP per-worker in }(\mathcal{P})\end{array}$} \\
\hline \multicolumn{5}{|l|}{ Equal Human Capital $h_{\mathcal{R}} / h_{\mathcal{P}}=1.0$} \\
\hline No skill losses $(\theta=0.0)$ & 26.6 & 26.6 & $>99$ & -5.0 \\
\hline Skill losses $(\theta=0.15)$ & 26.6 & 26.6 & $>99$ & -5.0 \\
\hline \multicolumn{5}{|l|}{ Different Human Capital $h_{\mathcal{R}} / h_{\mathcal{P}}=1.5$} \\
\hline No skill losses $(\theta=0.0)$ & 25.3 & 25.3 & 93 & -4.8 \\
\hline Skill losses $(\theta=0.15)$ & 14.6 & 14.6 & 74 & -2.8 \\
\hline
\end{tabular}

Note: This table reports the steady-state effects on aggregate output, capital, the location of the labor force and output per-worker in the rich location driven by a removal of barriers to labor mobility. This is done for the cases of no-moving costs, and moving costs equal to $1 / 2$ annual output per worker in the poor location. For each case, results are reported for $50 \%$ differences in labor quality in favor of the rich location $\left(h_{\mathcal{R}} / h_{\mathcal{P}}=1.5\right)$, and no differences in labor quality $\left(h_{\mathcal{R}} / h_{\mathcal{P}}=1.0\right)$, with and without efficiency losses associated to migrating $(\theta=0.15$ and $\theta=0$ respectively). 
Table 3: Decomposition of World Output Changes

\begin{tabular}{|l|c|c|c|}
\hline Economy & $\begin{array}{c}\text { Only Labor } \\
\text { Movements } \\
(1)\end{array}$ & $\begin{array}{c}\text { Labor Movements- } \\
\text { New Division of K } \\
(2)\end{array}$ & $\begin{array}{c}\text { Total } \\
\text { Change } \\
(3)\end{array}$ \\
\hline Equal Human Capital $h_{\mathcal{R}} / h_{\mathcal{P}}=1.0$ & 3.5 & 17.5 & 26.6 \\
No skill losses $(\theta=0.0)$ & 4.0 & 17.5 & 26.6 \\
Skill losses $(\theta=0.15)$ & & & \\
Different Human Capital $h_{\mathcal{R}} / h_{\mathcal{P}}=1.5$ & 7.2 & 16.7 & 25.3 \\
No skill losses $(\theta=0.0)$ & 7.8 & 9.7 & 14.6 \\
Skill losses $(\theta=0.15)$ & & & \\
\hline
\end{tabular}

Note: This table decomposes the steady-state effects on aggregate output driven by a removal of barriers to labor mobility into a part attributable only to labor movements, a part due to the reallocation of capital across locations and a part due to increases in the capital stock. Results are shown for moving costs equal to $1 / 2$ annual output per worker in the poor location, with and without differences in labor quality, and with and without losses of efficiency units. Specifically, the table shows (i) the increase in world output due exclusively to movements of labor (i.e for a given world capital stock and a given division between locations); (ii) the increase in world output due to the movement of labor, for the old capital stock under its new division; (iii) the total increase in world output. 


\section{Table 4: Effects on Aggregate (World) Output}

(Percentage increase with respect to the initial steady state)

\begin{tabular}{|c|c|c|c|}
\hline Economy & 10 Years & 25 Years & 50 Years \\
\hline \multicolumn{4}{|c|}{ Case I: Enlargement of European Union } \\
\hline \multicolumn{4}{|l|}{ High Psychic Costs } \\
\hline$\overline{\text { No skill losses }(\theta=0.0)}$ & 0.32 & 0.90 & 2.36 \\
\hline Skill losses $(\theta=0.15)$ & 0.18 & 0.58 & 1.74 \\
\hline \multicolumn{4}{|l|}{ Low Psychic Costs } \\
\hline$\overline{\text { No skill losses }(\theta=0.0)}$ & 0.65 & 1.75 & 4.54 \\
\hline Skill losses $(\theta=0.15)$ & 0.42 & 1.28 & 3.32 \\
\hline \multicolumn{4}{|c|}{ Case II: Common Labor Market in NAFTA } \\
\hline \multicolumn{4}{|l|}{ High Psychic Costs } \\
\hline$\overline{\text { No skill losses }(\theta=0.0)}$ & 0.18 & 0.52 & 1.63 \\
\hline Skill losses $(\theta=0.15)$ & 0.11 & 0.38 & 1.27 \\
\hline \multicolumn{4}{|l|}{ Low Psychic Costs } \\
\hline$\overline{\text { No skill losses }(\theta=0.0)}$ & 0.36 & 1.01 & 3.04 \\
\hline Skill losses $(\theta=0.15)$ & 0.22 & 0.74 & 2.41 \\
\hline
\end{tabular}

Note: This table reports the effects on aggregate output along the transition path driven by removing (unexpectedly) barriers to labor mobility. For every parameterization (EU, Nafta), we report results for two cases (high and low psychic costs), with and without skill losses associated to migration. The case of high psychic costs corresponds to emigration rates in the first 25 years averaging about 0.5 percent per-annum, whereas the case of low psychic cost corresponds to emigration rates in the first 25 years averaging 1.0 percent per-annum. 
Table 5: Population in Rich Location

(Percentage increase with respect to the initial steady state)

\begin{tabular}{|l|r|r|r|}
\hline Economy & 10 Years & 25 Years & 50 Years \\
\hline Case I: Enlargement of European Union & & & \\
High Psychic Costs & & & \\
\hline No skill losses $(\theta=0.0)$ & 1.0 & 2.5 & 4.8 \\
Skill losses $(\theta=0.15)$ & & 2.5 & 4.9 \\
Low Psychic Costs & 1.8 & 5.0 & 8.8 \\
\hline No skill losses $(\theta=0.0)$ & 1.8 & 5.0 & 8.5 \\
Skill losses $(\theta=0.15)$ & & & \\
\hline \hline Case II: Common Labor Market in NAFTA & & & \\
High Psychic Costs & 1.2 & 2.8 & 4.9 \\
\hline No skill losses $(\theta=0.0)$ & & 2.8 & 4.4 \\
Skill losses $(\theta=0.15)$ & & & \\
Low Psychic Costs & & & \\
\hline No skill losses $(\theta=0.0)$ & & 5.5 & 9.1 \\
Skill losses $(\theta=0.15)$ & & 5.5 & 8.3 \\
\hline
\end{tabular}

Note: This table reports the effects on the population of the rich location along the transition path driven by removing (unexpectedly) barriers to labor mobility. For every parameterization (EU, Nafta), we report results for two cases (high and low psychic costs), with and without skill losses associated with changing locations. The case of high psychic costs corresponds to emigration rates in the first 25 years averaging about 0.5 percent per-annum, whereas the case of low psychic cost corresponds to emigration rates in the first 25 years averaging 1.0 percent per-annum. 
Table 6: Welfare Gains: Enlargement of EU

\begin{tabular}{|c|c|c|c|c|}
\hline No Skill & \multicolumn{2}{|c|}{ Natives of Rich Location } & \multicolumn{2}{|c|}{ Natives of Poor Location } \\
\hline Losses & Low Psychic Costs & High Psychic Costs & Low Psychic Costs & High Psychic Costs \\
\hline Generation & & & & \\
\hline 1 & 0.05 & 0.03 & -0.28 & -0.14 \\
\hline 6 & 0.28 & 0.14 & 10.88 & 5.27 \\
\hline 12 & -0.57 & -0.29 & 5.86 & 2.90 \\
\hline 24 & -0.82 & -0.50 & 11.36 & 5.54 \\
\hline Skill Losses & \multicolumn{2}{|c|}{ Natives of Rich Location } & \multicolumn{2}{|c|}{ Natives of Poor Location } \\
\hline$(\theta=0.15)$ & Low Psychic Costs & High Psychic Costs & Low Psychic Costs & High Psychic Costs \\
\hline Generation & & & & \\
\hline 1 & 0.05 & 0.02 & -0.26 & -0.12 \\
\hline 6 & 0.21 & 0.0 & 10.03 & 4.23 \\
\hline 12 & -0.41 & -0.18 & 6.20 & 2.68 \\
\hline 24 & -0.84 & -0.56 & 11.05 & 5.26 \\
\hline
\end{tabular}

Note: This table presents welfare gains (expressed as percentage compensating variations) for the case of EU enlargement. Generation 1 corresponds to those in the last period of their lives when barriers are removed, $t=t_{0}$. Generation 12 corresponds to those born at $t=t_{0}$. Generation 24 corresponds to those born 12 periods after $t=t_{0}$. The case of high psychic costs corresponds to emigration rates in the first 25 years averaging about 0.5 percent per-annum, whereas the case of low psychic cost corresponds to emigration rates in the first 25 years averaging 1.0 percent per-annum. 
Table 7: Welfare Gains: Common Labor Market in NAFTA

\begin{tabular}{|c|c|c|c|c|}
\hline No Skill & \multicolumn{2}{|c|}{ Natives of Rich Location } & \multicolumn{2}{|c|}{ Natives of Poor Location } \\
\hline Losses & Low Psychic Costs & High Psychic Costs & Low Psychic Costs & High Psychic Costs \\
\hline Generation & & & & \\
\hline 1 & 0.04 & 0.02 & -0.17 & -0.09 \\
\hline 6 & 0.17 & 0.09 & 4.71 & 2.31 \\
\hline 12 & -0.33 & -0.17 & 3.95 & 1.97 \\
\hline 24 & -0.91 & -0.53 & 8.31 & 4.12 \\
\hline Skill Losses & \multicolumn{2}{|c|}{ Natives of Rich Location } & \multicolumn{2}{|c|}{ Natives of Poor Location } \\
\hline$(\theta=0.15)$ & Low Psychic Costs & High Psychic Costs & Low Psychic Costs & High Psychic Costs \\
\hline Generation & & & & \\
\hline 1 & 0.04 & 0.02 & -0.17 & -0.09 \\
\hline 6 & 0.11 & 0.05 & 4.10 & 1.96 \\
\hline 12 & -0.24 & -0.12 & 4.35 & 2.20 \\
\hline 24 & -0.83 & -0.48 & 7.71 & 3.96 \\
\hline
\end{tabular}

Note: This table presents welfare gains (expressed as compensating variations) for the case of the creation of a common labor market within NAFTA. Generation 1 corresponds to those in the last period of their lives when barriers are removed, $t=t_{0}$. Generation 12 corresponds to those born at $t=t_{0}$. Generation 24 corresponds to those born 12 periods after $t=t_{0}$. The case of high psychic costs corresponds to emigration rates in the first 25 years averaging about 0.5 percent per-annum, whereas the case of low psychic cost corresponds to emigration rates in the first 25 years averaging 1.0 percent per-annum. 


\section{Table 8: Effects on Aggregate (World) Output and Population in the Rich Location}

(Percentage increase with respect to the initial steady state)

\begin{tabular}{|l|r|r|r|}
\hline Variable & 10 Years & 25 Years & 50 Years \\
\hline Aggregate Output & & & \\
\hline Benchmark & & & \\
No Resource Costs & 0.22 & 0.74 & 2.41 \\
No Borrowing Constraints & 0.35 & 1.02 & 3.04 \\
None & 0.61 & 1.56 & 4.26 \\
& 0.75 & 1.79 & 4.73 \\
Population in the Rich Location & & & \\
\hline & & & \\
Benchmark & 2.06 & 5.48 & 8.26 \\
No Resource Costs & 3.36 & 6.85 & 9.83 \\
No Borrowing Constraints & 6.29 & 9.67 & 13.31 \\
None & 7.22 & 10.66 & 14.35 \\
& & & \\
\hline
\end{tabular}

Note: This table reports the effects on aggregate output and population in the rich location along the transition path driven by removing (unexpectedly) barriers to labor mobility. In addition to the benchmark case, three additional cases are reported (i) no resource costs; (ii) no borrowing constraints; (iii) neither resource costs nor borrowing constraints. This is done for the NAFTA case with $\theta=0.15$, under the distribution of psychic costs corresponding to the $1 \%$ emigration rate per-annum in the benchmark case. 


\section{References}

Alvarez, F., \& Lucas, R. (2006). General Equilibrium Analysis of the Eaton-Kortum Model of International Trade. Mimeo.

Auerbach, A. J., \& Kotlikoff, L. J. (1987). Dynamic Fiscal Policy. Cambridge University Press, New York.

Barro, R., \& Sala-i-Martin, X. (1999). Economic Growth. Cambridge, Massachusetts and London, England: MIT Press.

Barro, R. J., \& Lee, J. W. (2000). International Data on Educational Attainment: Updates and Implications. Manuscript, Harvard University.

Ben-Gad, M. (2004). The Economic Effects of Immigration: a Dynamic Analysis. Journal of Economic Dynamics and Control, 28(9), 1825-1845.

Borjas, G. J. (1995). The Economics Benefits from Immigration. Journal of Economic Perspectives, 9(2), 3-22.

Borjas, G. J. (1996). The Earnings of Mexican Immigrants in the United States. Journal of Development Economics, 51(1), 69-98.

Browning, M., Hansen, L., \& Heckman, J. (1999). Micro Data and General Equilibrium Models. In Taylor, J., \& Woodford, M. (Eds.), Handbook of Macroeconomics. Elsevier Science, B.V., Amsterdam, The Netherlands.

Burstein, A., \& Monge, A. (2005). Aggregate Consequences of Foreign Firms in Developing Countries. Mimeo.

Carey, D., \& Rabesona, J. (2002). Tax Ratios on Labour and Capital and on Consumption. OECD Economic Studies, 35, 129-174.

Caselli, F. (2004). Accounting for Cross-Country Income Differences. Forthcoming, Handbook of Economic Growth.

Caselli, F., \& Coleman, J. (2001). The U.S. Structural Transformation: A Reinterpretation. Journal of Political Economy, 109 (3), 584-616.

Caselli, F., \& Feyrer, J. (2005). The Marginal Product of Capital. Forthcoming, Quarterly Journal of Economics.

Commission of the European Communities (2006). Report on the Functioning of Transitional Arrangements set out in the 2003 Accession Treaty. Brussels.

Cooley, T. F., \& Prescott, E. C. (1995). Economic Growth and Business Cycles. In Cooley, T. F. (Ed.), Frontiers of Business Cycle Research, chap. 1. Princeton University Press, Princeton. 
Crucini, M., \& Kahn, J. (2003). Tariffs and the Great Depression Revisited. Manuscript.

de Melo, J., \& Tarr, D. (1992). A General Equilibrium Analysis of U.S. Foreign Trade Policy. MIT Press. Cambridge, MA.

Gollin, D. (2002). Getting Income Shares Right. Journal of Political Economy, 110(2), $458-474$.

Gourinchas, P.-O., \& Jeanne, O. (2006). The Elusive Gains from International Financial Integration. Review of Economic Studies, $73(3)$.

Hall, R., \& Jones, C. (1999). Why Do Some Countries Produce So Much More Output per Worker than Others? Quarterly Journal of Economics, 114(1), 83-116.

Hamilton, B., \& Whalley, J. (1984). Efficiency and Distributional Implications of Global Restrictions on Labour Mobility: Calculations and Policy Implications. Journal of Development Economics, 14(1-2), 61-75.

Hatton, T., \& Williamson, J. (1998). The Age of Mass Migration: An Economic Analysis. New York: Oxford University Press.

Hendricks, L. (2002). How Important is Human Capital for Development? Evidence from Immigrant Earnings. American Economic Review, 92(1), 198-219.

Klein, P., \& Ventura, G. (2006). TFP Differences and the Aggregate Effects of Labor Mobility in the Long Run. Manuscript.

Klenow, P., \& Rodriguez-Clare, A. (1997). The Neoclassical Revival in Growth Economics: Has It Gone Too Far? In Bernanke, B., \& Rotemberg, J. (Eds.), NBER Macro Annual. MIT Press.

Lucas, R. E. (1990). Supply Side Economics: An Analytical Review. Oxford Economic Papers, 42, 293-316.

Maddison, A. (1995). Monitoring the world economy, 1820-1992. Paris: Development Centre of the Organisation for Economic Co-operation and Development.

McGrattan, E., \& Schmitz, J. (2000). Explaining Cross-Country Income Differences. In Taylor, J., \& Woodford, M. (Eds.), Handbook of Macroeconomics, chap. 3. Elsevier.

Mendoza, E. G., Razin, A., \& Tesar, L. L. (1994). Effective tax rates in macroeconomics Cross-country estimates of tax rates on factor incomes and consumption. Journal of Monetary Economics, 34(3), 297-323.

Mitchell, B. R. (1998). International Historical Statistics 1750-1993. New York: Stockton Press. 
Moses, J., \& Letnes, B. (2004). The Economic Costs to International Labor Restrictions: Revisiting the Empirical Discussion. World Development, 32(10), 1609-1626.

Mundlak, Y. (2001). Production and Supply. In Gardner, B., \& Rausser, G. (Eds.), Handbook of Agricultural Economics, chap. 1. Elsevier Science B.V.

O'Rourke, K., \& Williamson, J. (1999). Globalization and History: The Evolution of the Nineteenth-Century Atlantic Economy. Cambridge, Massachusetts: MIT Press.

Parente, S., \& Prescott, E. (2000). Barrieres to Riches. MIT Press, Cambridge.

Prescott, E. (1998). Needed: A Theory of Total Factor Productivity. International Economic Review, $39(3)$, 525-551.

Rao, D. S. P. (1993). Intercountry comparisons of agricultural output and productivity. Rome: Food and Agricultural Organization of the United Nations.

Simpson, N. (2000). The Effects of Redistributive Policies on Education and Migration. Manuscript, Colgate University.

Storesletten, K. (1996). The Economics of Immigration. Ph.D. thesis, Carnegie Mellon University.

Urrutia, C. (1998). On the Self-Selection of Immigrants. Manuscript, Universidad Carlos III de Madrid.

Vandenbroucke, G. (2007). The U.S. Westward Expansion. Forthcoming, International Economic Review.

Walmsley, T. L., \& Winters, L. A. (2003). Relaxing Restrictions on Temporary Movements of Natural Persons: A Simulation Analysis. CEPR Discussion Paper \# 3719. 